\title{
Cruise Speed Sensitivity Study for Transonic Truss Braced Wing
}

\author{
Douglas P. Wells ${ }^{\dagger}$ \\ NASA Langley Research Center, Hampton, VA, 23681
}

\begin{abstract}
NASA's investment and research in aviation has led to new technologies and concepts that make aircraft more efficient and environmentally friendly. One aircraft design operational concept is the reduction of cruise speed to reduce fuel burned during a mission. Although this is not a new idea, it was used by all of the contractors involved in a 2008 NASA sponsored study that solicited concept and technology ideas to reduce environmental impacts for future subsonic passenger transports. NASA is currently improving and building new analysis capabilities to analyze advanced concepts. To test some of these new capabilities, a transonic truss braced wing configuration was used as a test case. This paper examines the effects due to changes in the design cruise speed and other tradeoffs in the design space. The analysis was baselined to the Boeing SUGAR High truss braced wing concept. An optimization was run at five different design cruise Mach numbers. These designs are compared to provide an initial assessment space and the parameters that should be considered when selecting a design cruise speed. A discussion of the design drivers is also included. The results show that the wing weight in the current analysis has more influence on the takeoff gross weight than expected. This effect caused lower than expected wing sweep angle values for higher cruise speed designs.
\end{abstract}

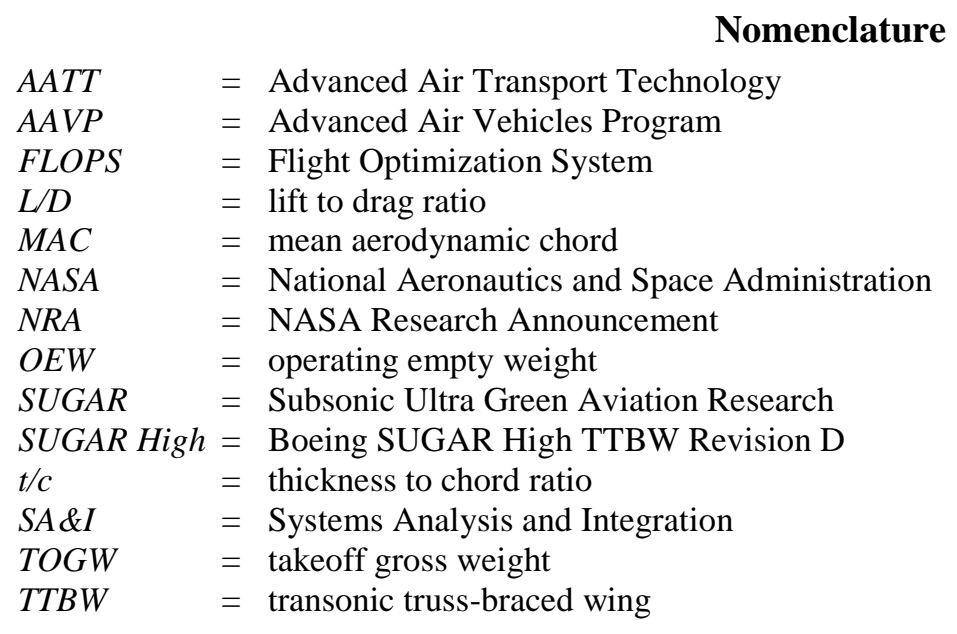

\section{Introduction}

WEW concepts and technologies could lead to drastic improvements in aircraft efficiency and operations. National Aeronautics and Space Administration's (NASA) Advanced Air Transport Technology (AATT) project is pursuing concepts and technologies that will reduce fuel burn, emissions, and noise significantly from current state-of-the-art commercial transport aircraft. In 2008, NASA awarded a NASA Research Announcement (NRA) titled, "Advanced Concept Studies for Subsonic Commercial Transport Aircraft Entering Service in the 2030-2035 Time Period" to solicit concept and technology ideas. The NRA included examination of future

\footnotetext{
${ }^{\dagger}$ Aerospace Engineer, Aeronautics Systems Analysis Branch, Mail Stop 442, AIAA Senior Member.
} 
operational requirements to describe future scenarios. One common theme from the responders was the reduction of aircraft cruise speed to enable lower fuel burn during missions. Boeing's proposed advanced concept aircraft had cruise speeds of Mach 0.7, the minimum allowed by their future scenario. This is a significant reduction from their reference vehicle's Mach 0.78 cruise speed, which is based on Boeing 737 class aircraft ${ }^{1}$. Traditionally as improvements in design and technology occurred since the time of the Wright Brothers first flight, speed and range have improved, with current modern day transports typically cruising at Mach 0.8 to 0.85 .

NASA is building and improving its current software capabilities to analyze advanced concepts. This paper presents a truss-braced wing aircraft configuration as a test case to evaluate these new capabilities. The specific aircraft selected is the Boeing Subsonic Ultra Green Aircraft Research (SUGAR) High Revision D ${ }^{2}$ (SUGAR High) transonic truss-braced wing (TTBW) configuration ${ }^{2}$. A cruise speed sensitivity study was performed to determine the impact on mission fuel. This study did not attempt to quantify the impact of cruise speed on the operational cost or productivity. The model was constructed with available analysis software at NASA Langley Research Center. Figure 1 shows an example of a TTBW configuration.

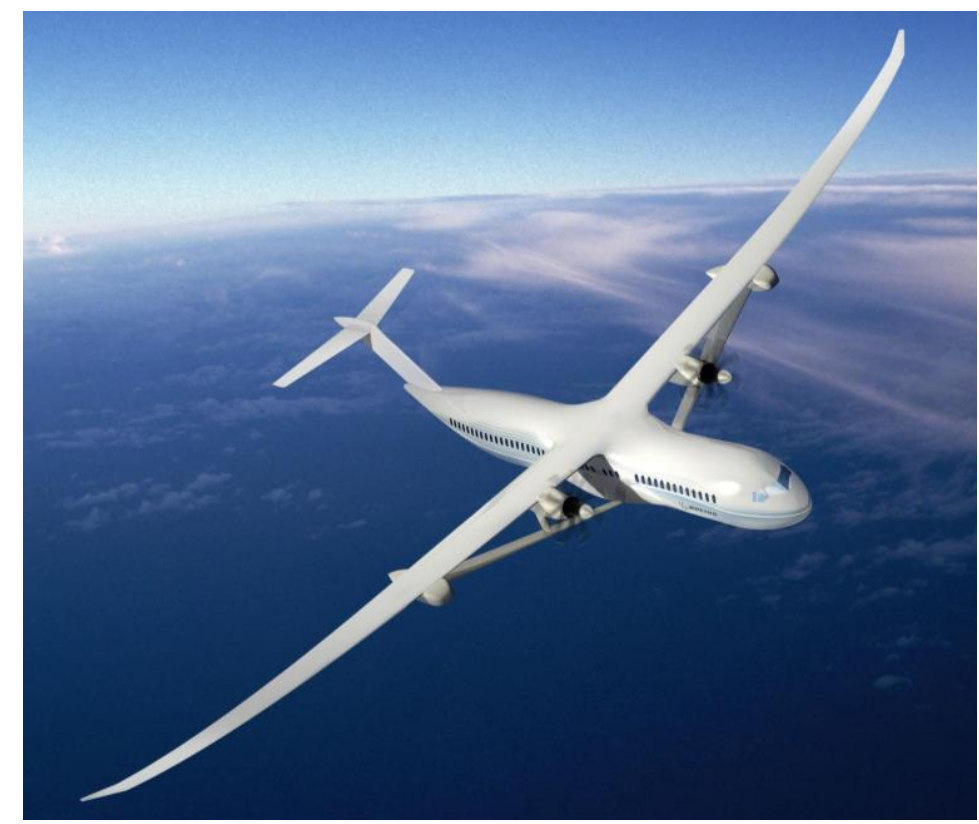

Figure 1. Boeing's SUGAR Volt, hybrid electric-gas propulsion concept.

\section{Problem Statement}

NASA is developing a robust sizing and scaling truss-braced wing aircraft process for analyzing applications of advanced technologies, changes in mission specifications, and changes in propulsion architecture. A cruise speed sensitivity study was used as an example case to exercise the truss-braced wing analysis process. A reasonable range to explore design cruise Mach numbers is $0.6-0.8 .^{2}$ The analysis was baselined to the Mach 0.7 Boeing SUGAR High TTBW configuration.

The sensitivity study was set up as an optimization problem. An optimization problem can be described mathematically as a search to minimize or maximize a particular design objective using a given set of design variables and constraints. Design constraints are used to bound the design space or limit the designs to feasible or useful products. Below is a description of the design objectives, variables, and constraints.

\section{A. Design Objective}

The design objective specifies the ultimate desire of the design. The sensitivity study is set up to show the impact of cruise speed on the takeoff gross weight (TOGW). Therefore, the design objective was to minimize the TOGW. Although minimizing the life cycle cost is a desired design objective, cost assessment was not part of the scope of this work. TOGW is often used as a proxy for life cycle cost in aircraft design exploration studies. Thus it will be used here. 


\section{B. Design Variables}

The design variables used in this study are limited to the wing geometry parameters and engine thrust. The number of design variables was arbitrarily limited to ten to enable faster design exploration time. The ten variables chosen include engine thrust, wing area, wing taper ratio, wing sweep, wing thickness-to-chord ratio, wing planform break location (this is also the strut attachment location on the wing), strut thickness-to-chord ratio, strut chord length, jury thickness-to-chord ratio, and jury chord length. The strut and truss members were allowed to translate and size as necessary to maintain their attachment locations. Table 1 shows the range limits for each design variable. Figure 2 is a visual description of the truss system members with a front view of a TTBW.

Table 1: Design Variable Matrix.

\begin{tabular}{|r|c|c|}
\hline & Units & \\
\hline Wing Variables Area & $\mathrm{ft}^{2}$ & $1,000-2,000$ \\
\hline Sweep & deg. & $0-35$ \\
\hline Thickness-to-Chord Ratio & & $0.05-0.25$ \\
\hline Strut Variables & & \\
\hline Thickness-to-Chord Ratio & & $0.1-0.2$ \\
\hline Jury Variables & & \\
\hline Thickness-to-Chord Ratio & & $0.1-0.2$ \\
\hline Propulsion Variables Thrust & $\mathrm{lb}$ & $15,000-35,000$ \\
\hline
\end{tabular}

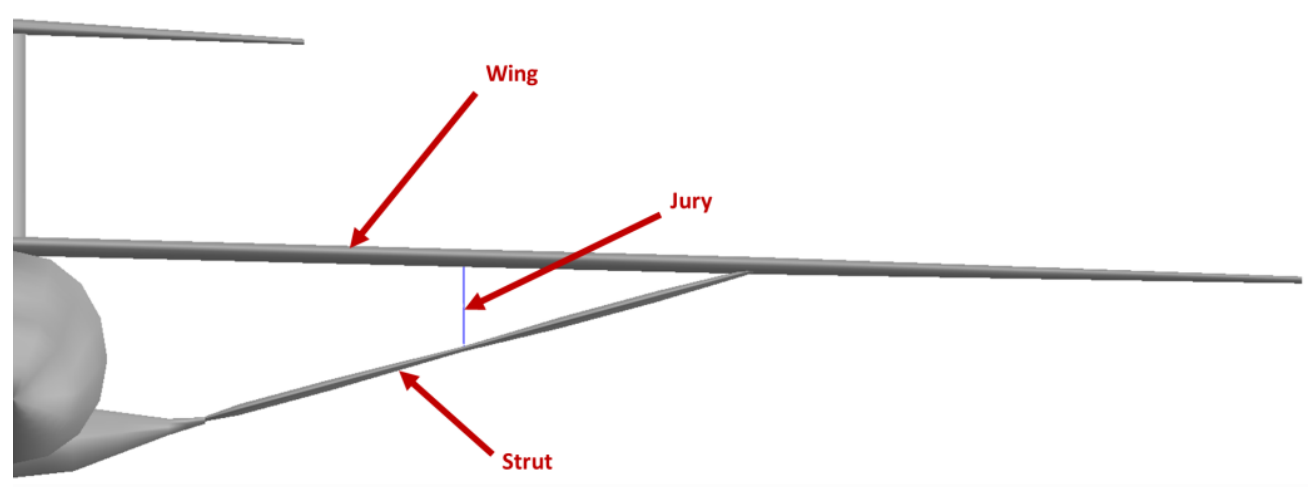

Figure 2. Truss System Description.

\section{Design Constraints}

The design constraints bound the problem. They are used in this study to ensure adequate aircraft performance. The design constraints that were used to design the Boeing SUGAR High configuration are not specified in the final report. Therefore, the constraints were selected to ensure that the resulting aircraft is at least as capable as the Boeing SUGAR High concept ${ }^{2}$. One exception is the approach speed. The maximum lift coefficient for the NASA model was lower than what Boeing assumed, therefore an approach speed limit was set closer to the Boeing 737 $800^{3}$. The design constraints are as follows:

1) Range: The range of the aircraft must be greater than or equal to $3,500 \mathrm{NM}$ with fuel to complete the reserve mission.

2) Approach Speed: The approach speed must not exceed 145 knots.

3) Takeoff Field Length: The takeoff field length must not exceed 7,680 feet.

4) Landing Field Length: The landing field length must not exceed 8,000 feet.

5) Missed Approach: The missed approach thrust margin with one engine inoperative must be greater than zero.

6) Second Segment Climb: The excess thrust available during the second segment climb with one engine inoperative must be greater than zero.

7) Excess Fuel Capacity: The wing must have enough fuel volume to carry the required mission fuel plus reserves. The excess fuel capacity must be greater than zero. 
8) Instantaneous Rate of Climb for Climb Ceiling: The instantaneous rate of climb for the climb ceiling must be $300 \mathrm{ft} / \mathrm{s}$.

\section{Assumptions}

Several assumptions were made and carefully considered in order to make the design problem more tractable and reduce the analysis time. The design variables were limited to the wing and truss geometry parameters, and maximum static thrust at sea level. Consequently, the fuselage and tail geometry are essentially fixed for all designs. A tail sizing routine is used in the optimization to size the horizontal and vertical tails ${ }^{4}$. Commercial aircraft technologies anticipated for entry into service in the 2030-35 period, market permitting, are used for this study, which is consistent with the SUGAR High design. A fixed mission was also assumed for all of the designs. The mission is equivalent to the SUGAR High design mission. A rubberized engine model with a reference sea-level static thrust of about 25,000 pounds is also used across all of the designs. A rubberized engine is a model with characteristics for a specific reference thrust that are scaled to model larger and smaller engines within a given tolerance.

\section{Analysis Process}

NASA, along with other research groups, desires the ability to run quick exploration and sensitivity studies on configurations. A parametric process was developed to model the truss-braced wing configuration. The process and quality of the model will be equivalent to recent industry work. The overall structure will be robust and capable of sizing, scaling, applying advanced technologies, changing mission specifications, and changing propulsion architecture. The end goal was an integrated analysis process that incorporates input data from higher order methods. The current process used for this study incorporates the Flight Optimization System (FLOPS) ${ }^{5}$ for weight estimation and mission analysis. The wing and truss weights and aerodynamics are estimated from a method that was developed by the Aerospace Systems Design Laboratory at Georgia Institute of Technology and the Multidisciplinary Analysis and Design Center for Advanced Vehicles at Virginia Polytechnic Institute and State University ${ }^{6}$. The current process does not capture the detailed coupling and interactions among different disciplines such as aerodynamics and structures. Like most methods, the current process estimates the aerodynamic loads and then uses them for the structural analysis. The detailed coupling and interactions would imply there is a feedback loop where the structural analysis results influence the aerodynamic analysis.

\section{Boeing SUGAR High Revision D Truss Braced Wing}

Boeing's SUGAR High truss-braced wing configuration has received a lot of attention recently because of numerous wind tunnel tests and design explorations. The availability of data made it a good example case for a truss-braced wing analysis process. The most recent set of complete data comes from Boeing's Phase II final report ${ }^{2}$. Therefore, the Revision D version will be used for the sensitivity study. First a baseline model of the SUGAR High configuration was created to highlight any differences in the analyses. Figure 3 shows the three-view of the SUGAR High Revision D configuration from Boeing's Phase II final report ${ }^{2}$. 


\begin{tabular}{|l|c|c|c|c|}
\hline Parameter & Units & $\begin{array}{c}\text { Total } \\
\text { Projected }\end{array}$ & $\begin{array}{c}\text { Horizontal } \\
\text { Stab. }\end{array}$ & $\begin{array}{c}\text { Vertical } \\
\text { Fin }\end{array}$ \\
\hline Area & ft. ${ }^{2}$ & 1477.11 & 296.24 & 297.69 \\
\hline Aspect Ratio & & 19.552 & 5.000 & 1.000 \\
\hline Span & in. & 2039.301 & 461.833 & 207.043 \\
\hline Taper Ratio & & 0.346 & 0.350 & 1.000 \\
\hline Root Chord & in. & 130.313 & 136.839 & 207.043 \\
\hline Tip Chord & in. & 45.135 & 47.894 & 207.043 \\
\hline Sweep 25\% & deg. & 12.52 & 20.63 & 41.00 \\
\hline MAC & in. & 110.286 & 99.504 & 207.043 \\
\hline Volume Coeff. & & & 1.5631 & 0.687 \\
\hline
\end{tabular}

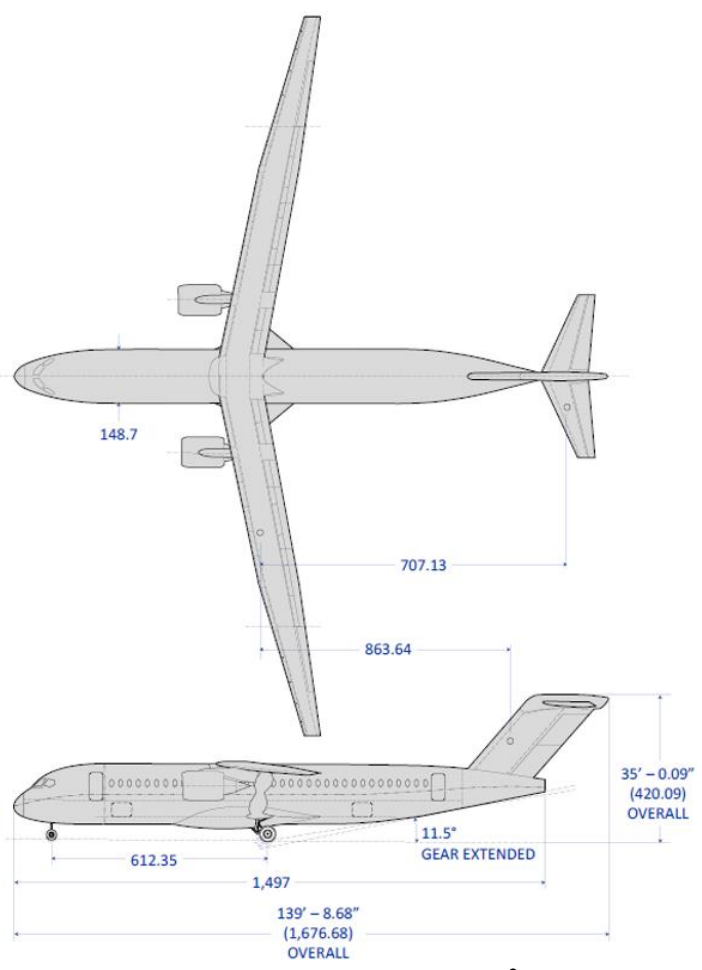

Figure 3. Boeing SUGAR High Revision D General Arrangement Drawing².

The NASA SUGAR High TTBW model was created using the SUGAR High "As Drawn" inputs from the Boeing SUGAR Phase II final report ${ }^{2}$. Some differences exist in geometry between the NASA and Boeing SUGAR High configurations, mostly due to rounding errors in an attempt to be consistent with the Boeing results. Once the results of the model were close to the Boeing results, the NASA SUGAR High TTBW was sized by varying wing area and takeoff thrust to obtain the minimum TOGW design. This was done in order to provide a link from this study to the Boeing SUGAR High TTBW. One notable difference in the design mission is that the NASA model assumes flight at a fixed Mach number at the optimum altitude for specific range while Boeing SUGAR High used a climbing cruise. Table 2 shows a comparison of the sized Boeing SUGAR High to the sized NASA TTBW model.

Table 2: Comparison of Boeing and NASA SUGAR High TTBW Configuration Mission Analysis Results.

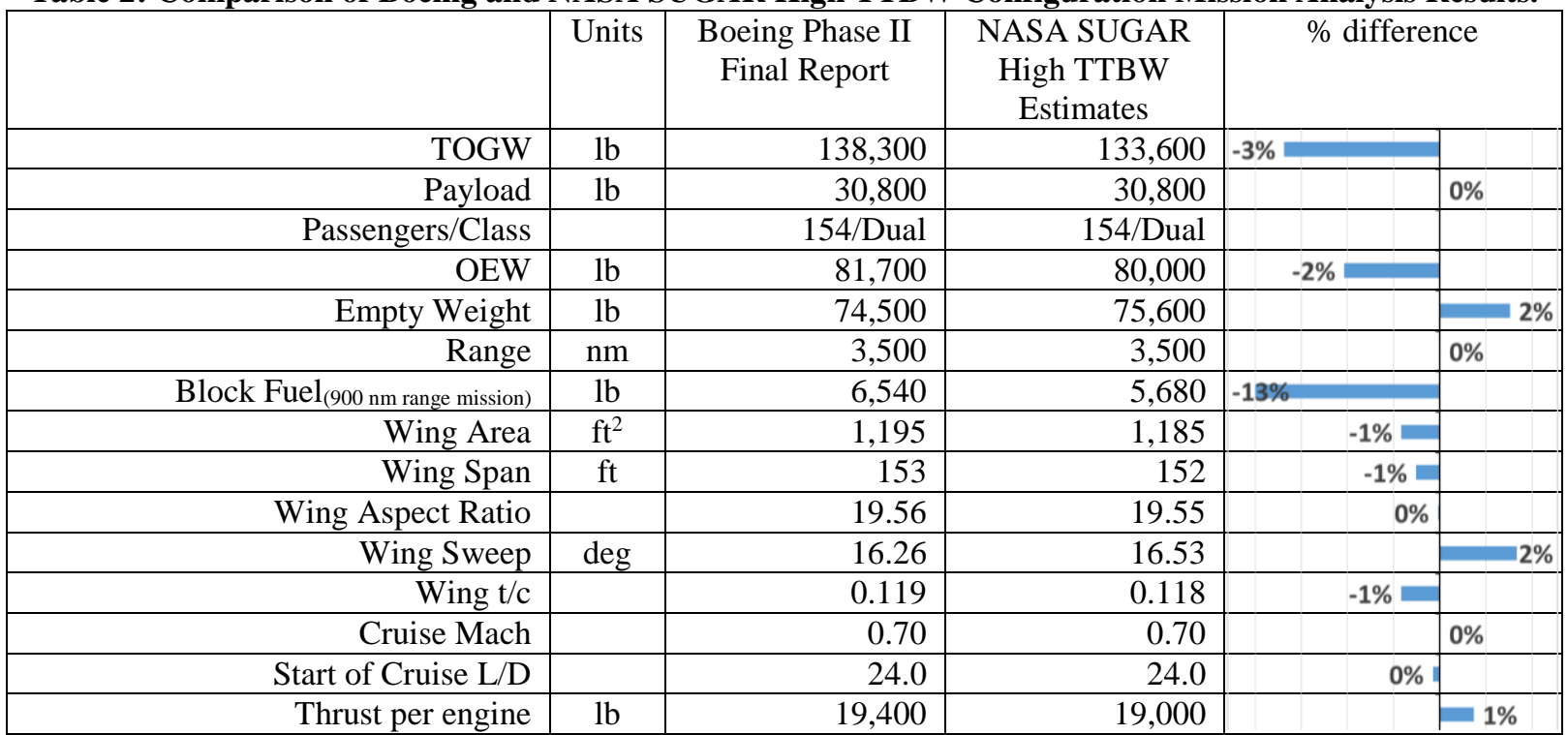


The NASA design sized at a little less than one percent lower wing area and higher thrust. The sizing was primarily constrained by the approach speed constraint, followed closely by the instantaneous rate of climb for climb ceiling constraint. The NASA model does assume different engine performance. Therefore, the block fuel is less for the NASA model due to the engine's lower specific fuel consumption. The NASA empty weight is higher than Boeing's estimate. However, the NASA operating items weight is less resulting in lower operating empty weight (OEW) and TOGW. Boeing did not provide a detailed breakdown of their operating item weights in the SUGAR Phase II final report ${ }^{2}$, so the cause of this difference is unknown. The wing sweep and thickness-to-chord ratio are identical, however the calculation for the total wing is different.

\section{Results}

The NASA TTBW model was optimized using the problem parameters discussed in Section II of this manuscript. It was assumed that the configurations flew their design mission at the design Mach number. Table 3 shows the TTBW design results. It is important to note that an "apples-to-apples" comparison of drag coefficients between designs is not possible as the geometries can be very different. The block fuel and time referred to throughout this manuscript are shown for a $900 \mathrm{~nm}$ average range mission and not the 3,500 $\mathrm{nm}$ design mission. This class of aircraft most commonly flies missions at shorter ranges than the design range. Reference 2 uses a similar average range mission when showing the fuel burn results.

Table 3: TTBW Cruise Mach Sensitivity Results.

\begin{tabular}{|c|c|c|c|c|c|c|}
\hline & Units & & & & & \\
\hline Cruise Mach Number & & 0.60 & 0.65 & 0.70 & 0.75 & 0.80 \\
\hline TOGW & $\mathrm{lb}$ & 126,900 & 128,000 & 129,700 & 132,500 & 144,600 \\
\hline OEW & $\mathrm{lb}$ & 74,500 & 75,700 & 76,900 & 78,300 & 85,900 \\
\hline Payload & $\mathrm{lb}$ & 30,800 & 30,800 & 30,800 & 30,800 & 30,800 \\
\hline Passengers/Class & & 154/Dual & 154/Dual & 154/Dual & 154/Dual & 154/Dual \\
\hline Range & $\mathrm{nm}$ & 3,500 & 3,500 & 3,500 & 3,500 & 3,500 \\
\hline Block Fuel $_{(900 \mathrm{~nm} \text { range) }}$ & $\mathrm{lb}$ & 5,290 & 5,320 & 5,520 & 5,880 & 6,840 \\
\hline Block Time $_{(900 \mathrm{~nm} \text { range) }}$ & $\mathrm{hr}$ & 3.0 & 2.8 & 2.7 & 2.6 & 2.5 \\
\hline Wing Area & $\mathrm{ft}^{2}$ & 1,130 & 1,150 & 1,150 & 1,180 & 1,320 \\
\hline Wing Span & $\mathrm{ft}$ & 149 & 150 & 150 & 152 & 161 \\
\hline Wing Aspect Ratio & & 19.55 & 19.55 & 19.55 & 19.55 & 19.55 \\
\hline Wing Sweep & $\operatorname{deg}$ & 3.76 & 4.31 & 5.40 & 6.56 & 17.23 \\
\hline Wing $\mathrm{t} / \mathrm{c}$ & & 0.148 & 0.121 & 0.107 & 0.107 & 0.107 \\
\hline Strut $t / c$ & & 0.198 & 0.155 & 0.156 & 0.100 & 0.100 \\
\hline Jury $t / c$ & & 0.119 & 0.196 & 0.121 & 0.195 & 0.122 \\
\hline Start of Cruise L/D & & 25.6 & 25.0 & 24.6 & 22.9 & 19.8 \\
\hline Thrust per engine & $\mathrm{lb}$ & 17,620 & 17,780 & 19,220 & 20,950 & 24,990 \\
\hline
\end{tabular}

As expected, the wing sweep angle increases with increasing Mach number. It is typically done to avoid the transonic flow effects which include drag rise. Figure 4 shows the significant increase in wave drag coefficient with Mach number. There is nearly zero wave drag at the 0.60 and 0.65 designs. As the wave drag increases it is necessary to increase the sweep to avoid some of the adverse effects. 


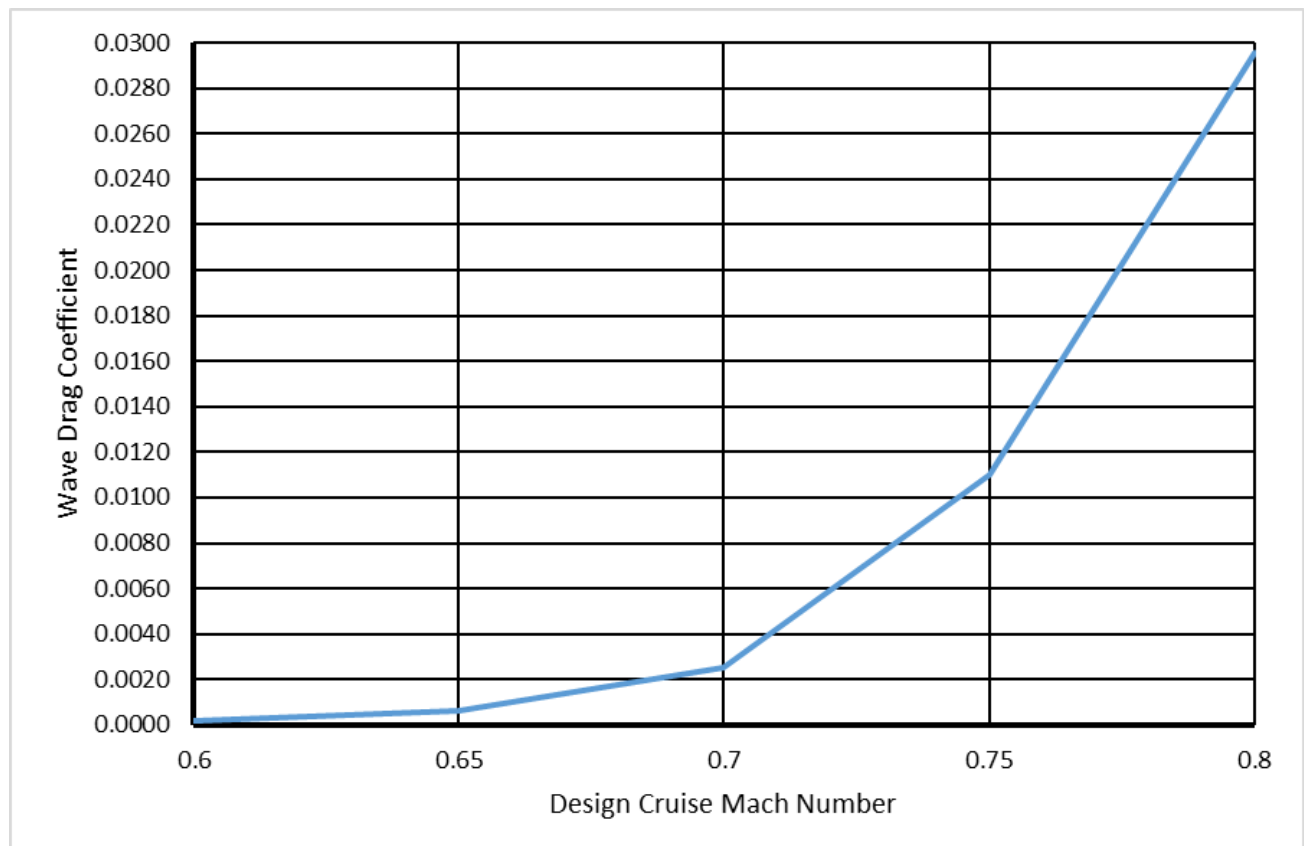

Figure 4. Wave Drag Coefficient Comparison.

Figure 5 shows the drag coefficient breakdown variation with wing sweep angle for the Mach 0.80 design. The increase in induced drag at sweep angles greater than about seventeen is very steep.

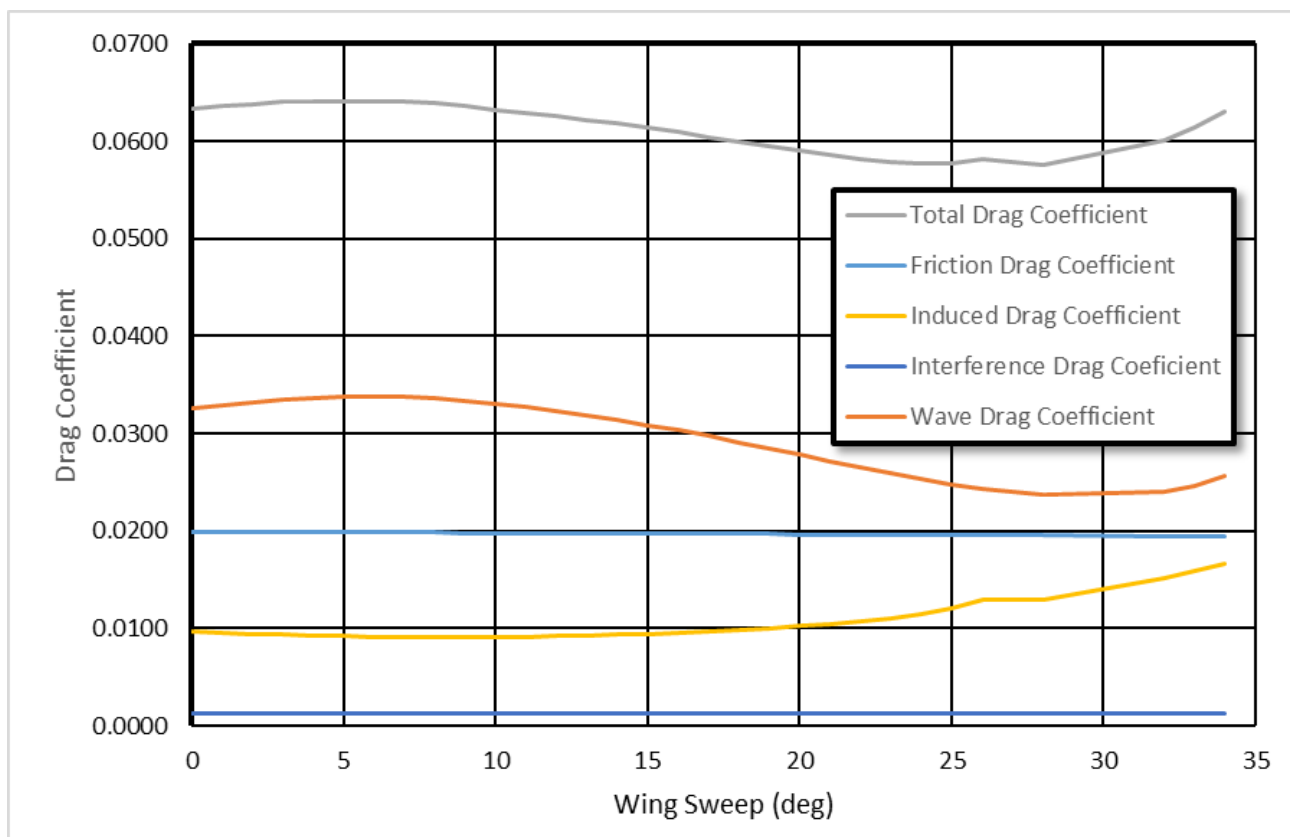

Figure 5. Variation of Component Drag Coefficients with Wing Sweep Angle Relative to the Optimized 0.80 Mach Design.

Figure 6 shows the drag breakdown for each design. Each Mach number features a different geometry which causes differences in the drag coefficients, so an "apples-to-apples" comparison is not possible. The wave drag coefficient is the largest variation as previously mentioned. This illustrates how the designs choose higher drag over more weight to keep the TOGW low. In other words, it costs more weight to increase wing sweep and keep wave drag low than it costs to decrease sweep and keep the wing weight low.

American Institute of Aeronautics and Astronautics 


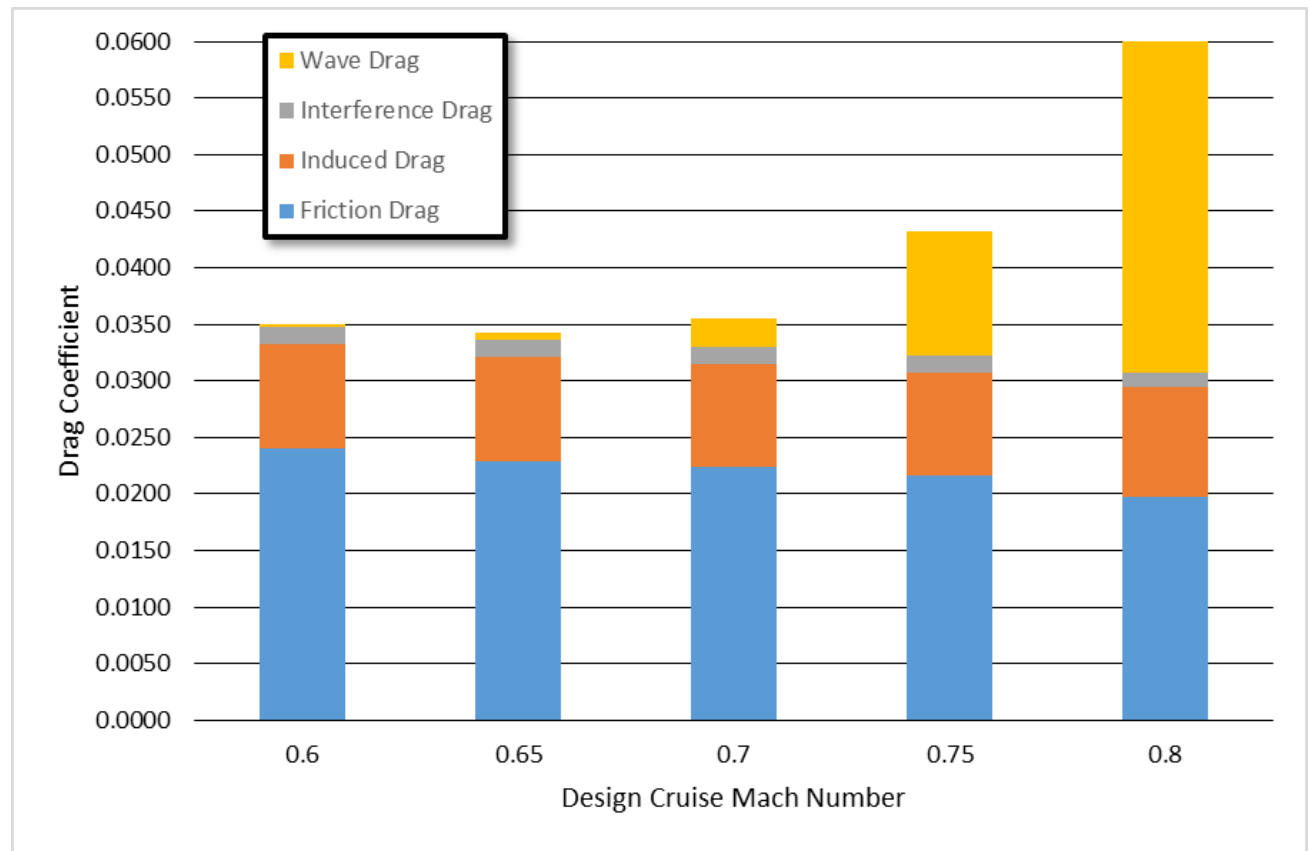

Figure 6. Drag Breakdown Comparison.

Figure 7 shows the weight of the wing, strut, and jury. It is clear that the increase in sweep at the Mach 0.80 design starts to increase the wing weight.

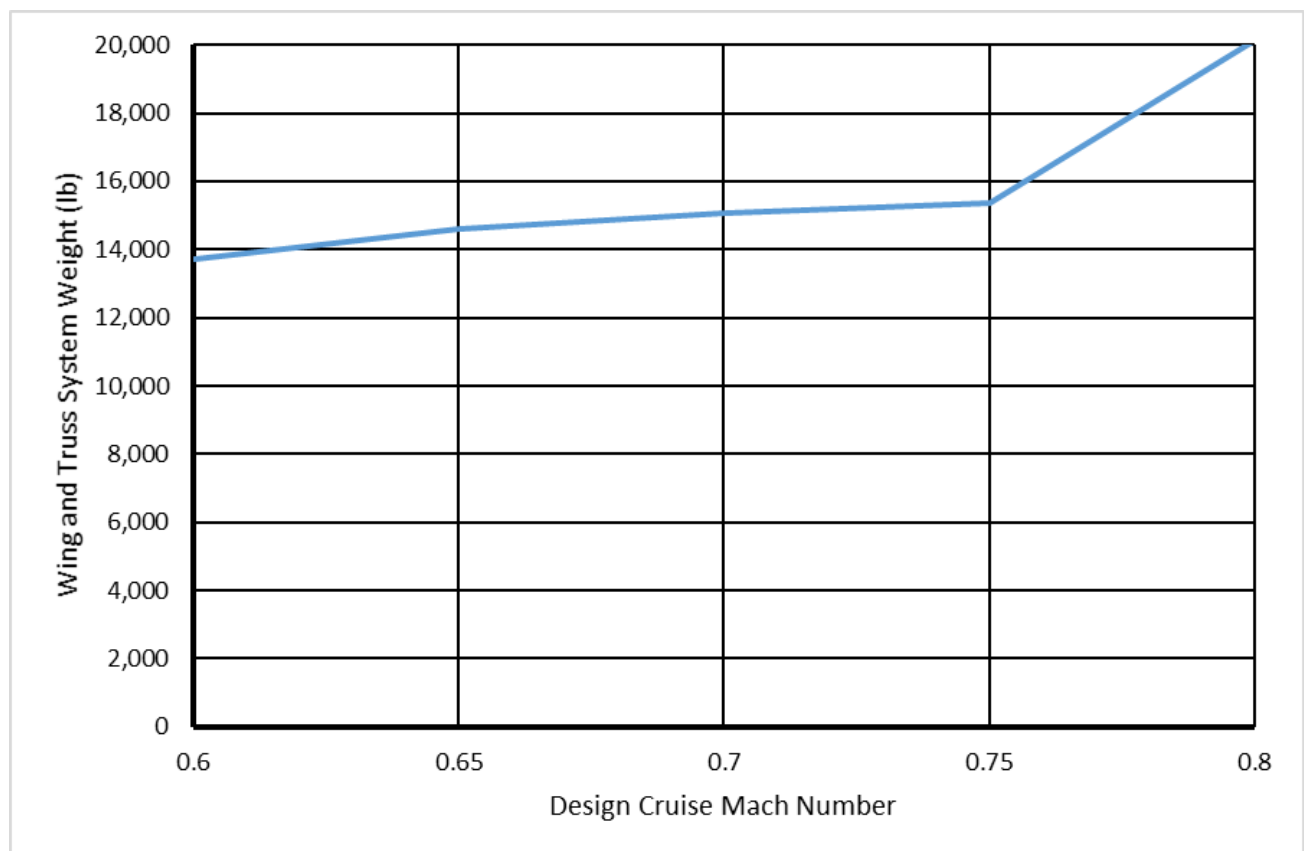

Figure 7. Wing and Truss System Weight comparison.

One of the interesting trends is the TOGW change with the design cruise Mach number. Figure 8 shows this trend for the optimized designs. Lower design cruise Mach number gives a lower TOGW. 


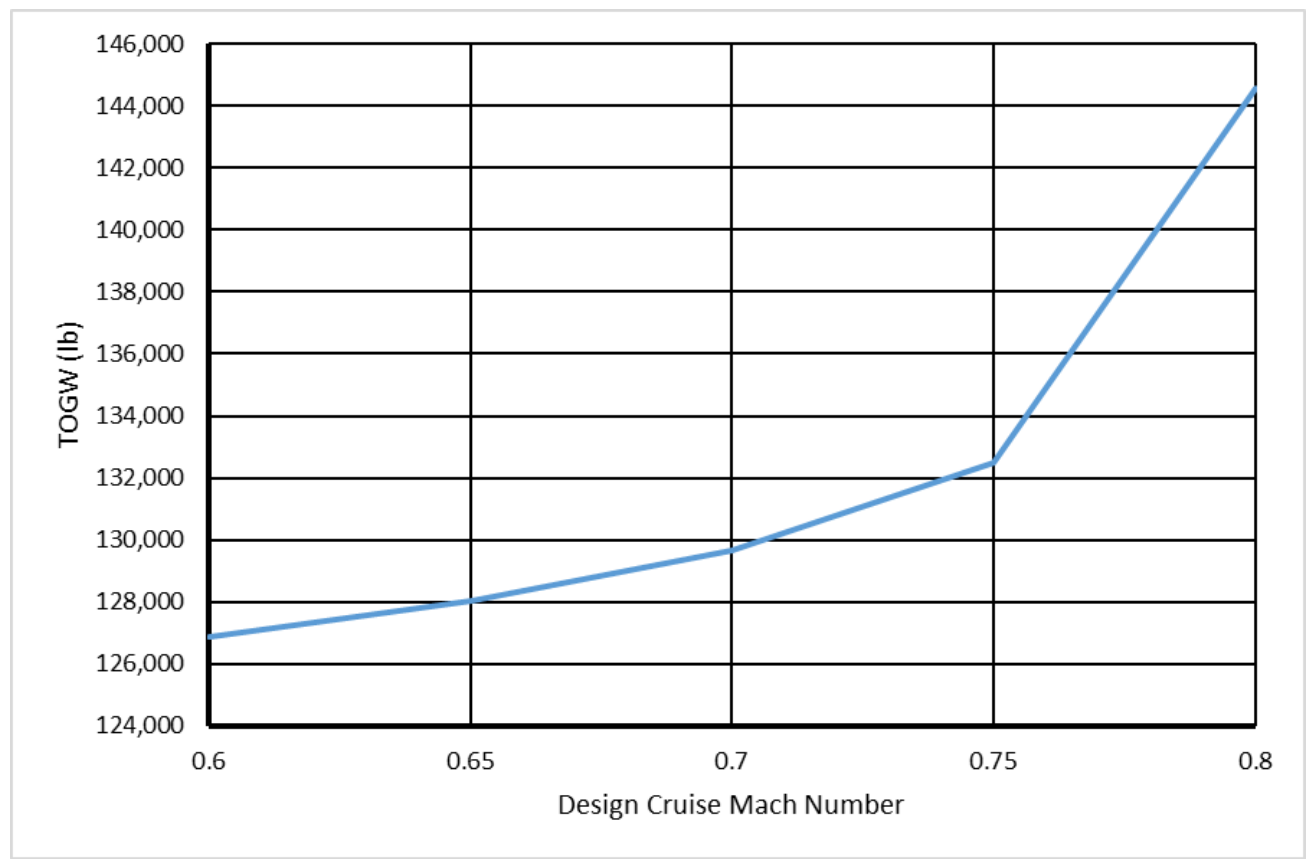

Figure 8. Takeoff Gross Weight Comparison.

Figure 9 shows the weight and drag tradeoff relative to the optimized design results. It is clear that the increase in wing weight with sweep angle is significant. This figure also shows that the minimum wave drag coefficient is around twenty-seven degrees of wing sweep. The minimum total drag coefficient is near the minimum wave drag coefficient, however the relative magnitude to the optimized design value is not as large.

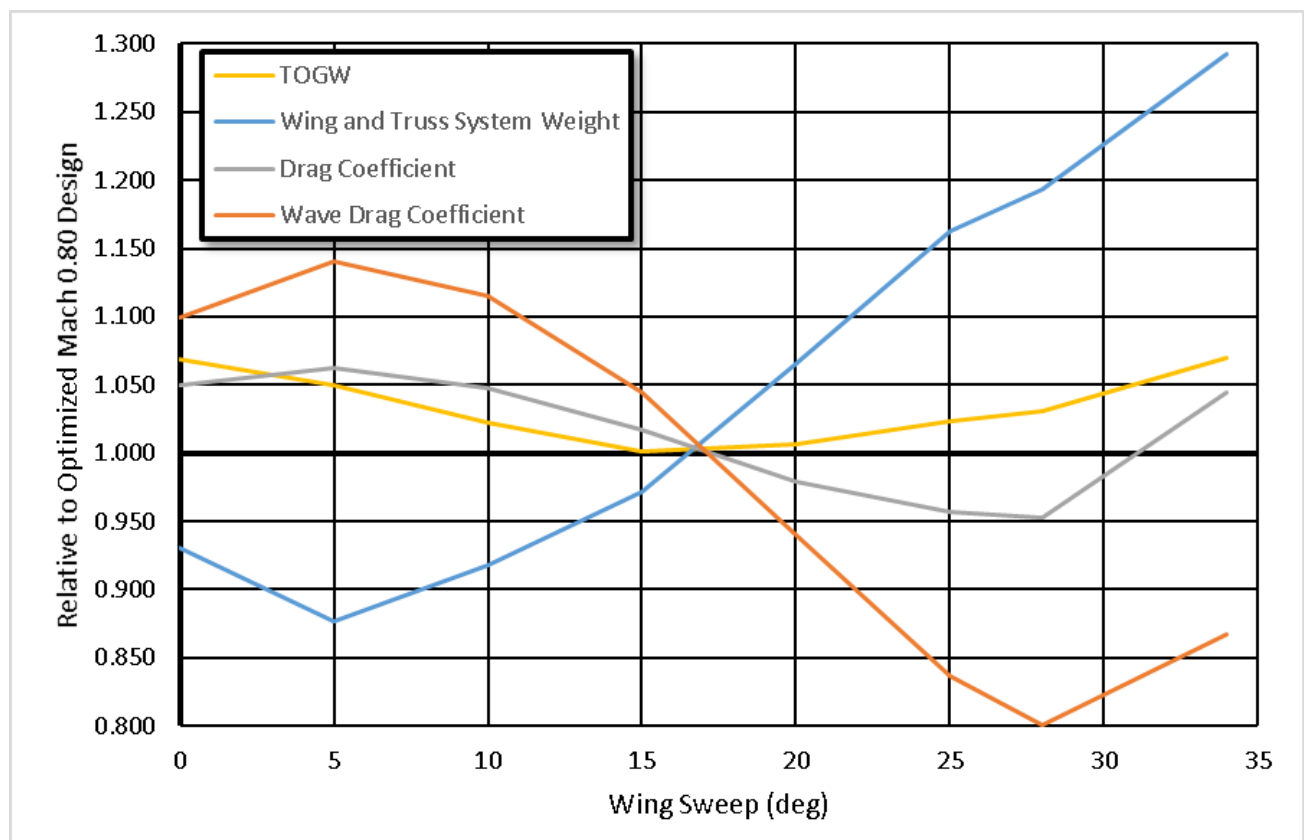

Figure 9. Variation of Weight and Drag with Wing Sweep Angle Relative to the Optimized 0.80 Mach Design.

Figure 10 shows the block fuel burned during the $900 \mathrm{~nm}$ average range mission. The trend is similar to the TOGW trend, but not at as steep of a slope. This is similar to the steadily increasing fuel burn with Mach number that Boeing showed in Figure 5.3 of Reference 1. 


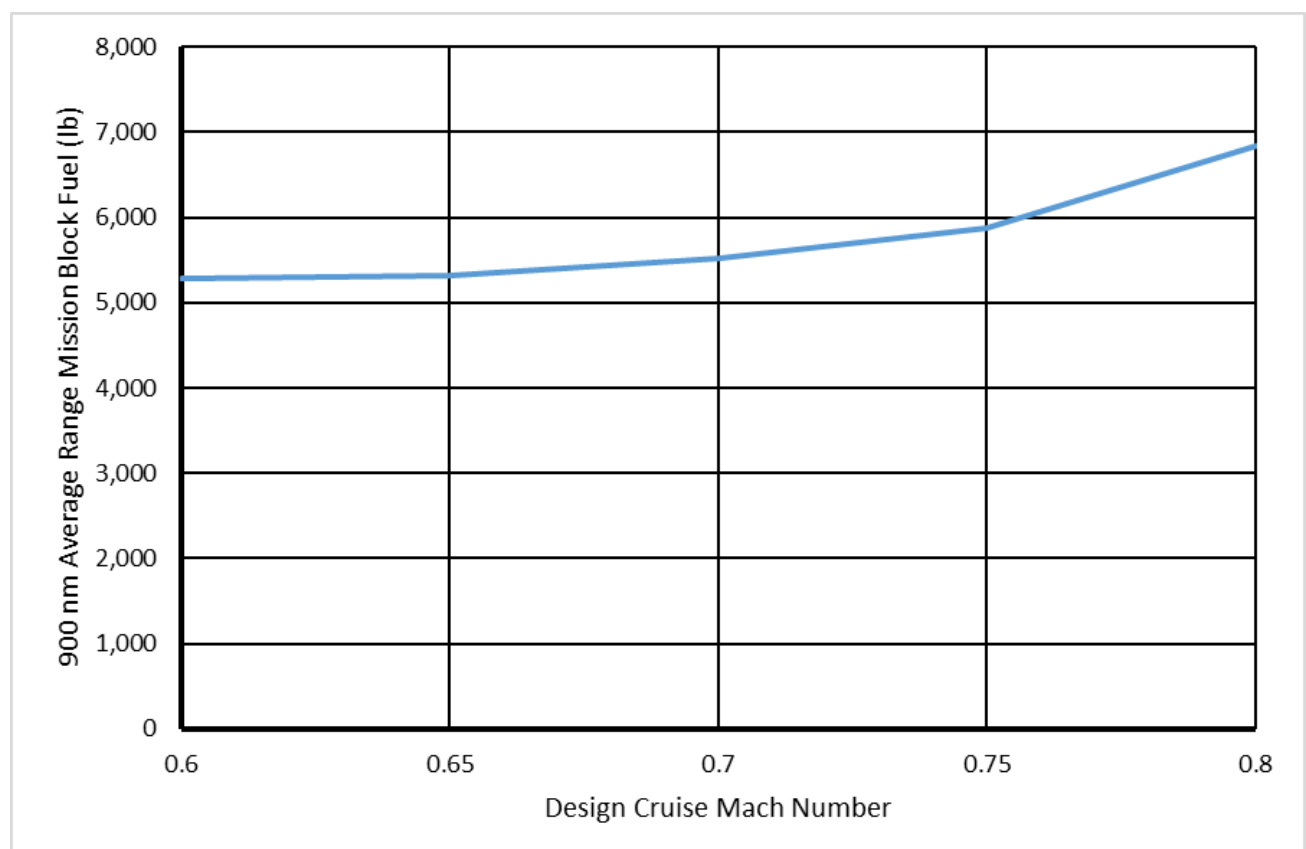

Figure 10. 900 nm Average Range Mission Block Fuel Comparison.

Figure 11 shows the block time for the $900 \mathrm{~nm}$ average range mission. As expected, flying at a lower speed will increase the amount of time to complete the mission. For the $900 \mathrm{~nm}$ mission this is almost a 30 minute or $16 \%$ time savings going from a Mach 0.60 cruise to Mach 0.80 cruise.

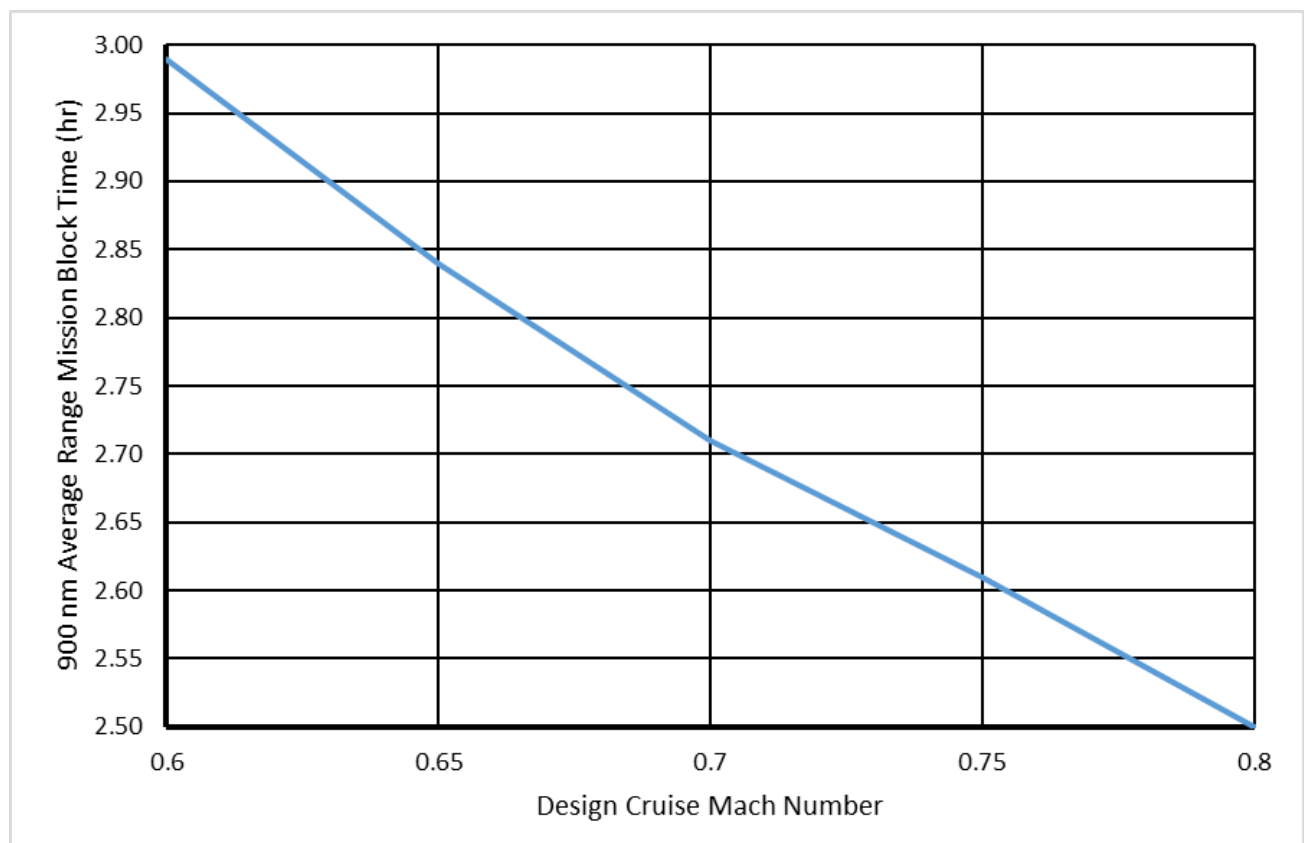

Figure 11. 900 nm Average Range Mission Block Time Comparison.

\section{Conclusions}

One interesting result was the high wave drag for the Mach 0.80 design. As shown, there is a significant increase in drag when designing at a higher Mach number. The optimizer could have increased the sweep of the design to reduce the wave drag. The optimizer instead chose a lower than expected wing sweep angle to keep the weight of the wing low. Figure 5 shows that increasing the wing sweep angle from seventeen degrees to about twenty-seven 
degrees will reduce the wave and total drag. The increase in induced drag at sweep angles greater than about seventeen is increasing the total drag and causing lower than expected wing sweep angles for the higher Mach number designs. The tradeoff should be examined more closely to ensure that the correct trend is modeled moving forward.

The tradeoff of design cruise speed usually balances the desired productivity of the aircraft and the value through cost. If TOGW can be assumed as a proxy for life cycle cost, slowing down the aircraft from the Boeing 737's 0.78 Mach cruise speed will decrease the life cycle cost. However, it will also slow down its productivity as the time to complete a given mission will increase. This will continue to be a tradeoff for new aircraft designs and NASA will continue to pursue technologies that will push the capabilities of transport aircraft. NASA's TTBW analysis process captured most of the trends expected for this cruise speed sensitivity study. The drag estimates produced trends that were not expected and require further investigation.

\section{Future Work}

The current analysis process provided a quick look at trends for a changing cruise speed. Some notable analyses that were missing are center of gravity, stability, and low speed aerodynamic estimations. Center of gravity was very crudely estimated based on geometry and initial weight estimations. The center of gravity estimation is used for stability and aerodynamic analysis and could provide additional design constraints. Stability was not estimated. The tail sizing routine should account for some stability, however a lot more is desired. Stability is sometimes overlooked and left until the end of a design cycle. It is important to consider the stability of a design early on to prevent unreasonable designs especially for new configurations. Low speed aerodynamics were not estimated. They were assumed to be equivalent performance to the baseline configuration. As the design changes, the low speed aerodynamic analysis needs to be performed to capture the effects on the takeoff and landing performance. This analysis process will continue to be improved to better assess advanced concepts like the transonic truss braced wing and to provide decision makers with more relevant data. There are many methods available to address the gaps mentioned. As time allows they should be incorporated into the process.

\section{Acknowledgments}

This work was completed with support from NASA's System Analysis and Integration group (SA\&I) under the Advanced Air Transport Technology (AATT) project in the Advanced Air Vehicles Program (AAVP). The author would like to thank Mark Guynn (NASA Langley Research Center) for his support of this research.

\section{References}

${ }^{1}$ Bradley, M. K. and Droney, C. K., "Subsonic Ultra Green Aircraft Research: Phase I Final Report," NASA CR-2011216847, April 2011.

${ }^{2}$ Bradley, M. K., Droney, C. K., and Allen, T. J., "Subsonic Ultra Green Aircraft Research Phase II: Volume I - Truss Braced Wing Design Exploration,” NASA CR-2015-218704, April 2015.

${ }^{3}$ Jackson, P., Munson, K., Peacock, L., and Bushell, S., Jane's All the World's Aircraft 2009-2010, Jane's Information Group, Surrey, UK, 2009, pp. 693.

${ }^{4}$ Morris, J. and Ashford, D., "Fuselage Configuration Studies," SAE Technical Paper 670370, 1967, doi:10.4271/670370

${ }^{5}$ McCullers, L.A., Aircraft Configuration Optimization Including Optimized Flight Profiles, Multi-disciplinary Analysis and Optimization Part 1, NASA CP-2327, 1984.

${ }^{6}$ Gur O., Bhatia M., Mason W.H., Schetz J.A., Kapania R.K., and T. Nam “Development of framework for truss-braced wing conceptual MDO," AIAA Paper 2010-2754, 6th AIAA Multidisciplinary Design Optimization Specialist Conference, April 1215, 2010, Orlando, Florida. 